\title{
Earth surface processes and their effects on human behavior in monsoonal China during the Pleistocene-Holocene epochs
}

\author{
LU Huayu ${ }^{1,2}$, ZHUO Haixin ${ }^{1}$, ZHANG Wenchao ${ }^{1}$, WANG Shejiang ${ }^{3}$, \\ ZHANG Hongyan ${ }^{1}$, SUN Xuefeng ${ }^{1}$, JIA Xin ${ }^{1}, X$ Zhiwei $^{1}$, WANG Xianyan ${ }^{1}$ \\ 1. School of Geographic and Oceanographic Sciences, Nanjing University, Nanjing 210023, China; \\ 2. CAS Center for Excellence in Tibetan Plateau Earth Sciences, Beijing 100101, China; \\ 3. Joint Laboratory of Human Evolution and Archaeometry, Institute of Vertebrate Paleontology and Paleoan- \\ thropology, CAS, Beijing 100044, China
}

\begin{abstract}
There is a wide diversity of landforms in China. The topography of three major terraces, decreasing in height stepwise from west to east, was formed by the early Miocene. With the commencement of the Great Northern Hemisphere Glaciations (GHGs) and the glacial-interglacial cycles in the Pleistocene, thick loess deposits accumulated in north China, and fluvial terraces were formed and lakes expanded and contracted in eastern and central China. The earliest evidence of hominins in China is dated to $\sim 1.7 \mathrm{Ma}$; they occupied the monsoon-dominated region for a long interval, until the late Pleistocene, $\sim 50 \mathrm{ka}$. In this study, we investigated a large area rich in the relics and artifacts of early man. The results indicate that the early humans occupied riverine areas, especially medium-sized fluvial basins, and lake shores. Even in the relatively recent geological past, the occupation and abandonment of settlements were directly forced by the shifting of sand dune fields in the desert-loess transitional zone, which in turn was closely associated with variations in the monsoon climate and vegetation patterns. Our observations indicate that landforms were one of the main determinants of early human behavior, in that loess tableland, large alluvial plains, desert-Gobi areas, and the Tibetan Plateau, were not suitable environments for early human settlement. We infer that the early humans in China adapted their behavior to specific landforms and landform processes. The monsoon climate, which shapes the large-scale step-like pattern of fluvial landforms, promotes vegetation coverage and dominates soil formation, provides a crucial context for early human adaptation. The adaptation of early humans to earth surface processes in East Asia is investigated for the first time in this study. Future investigations will provide further information that will increase our understanding of the linkage between early human behavior and landform processes in East Asia.
\end{abstract}

Keywords: earth surface processes; early human behavior; monsoon; Pleistocene; Holocene; China

Received: 2016-06-23 Accepted: 2017-07-31

Foundation: National Natural Science Foundation of China, No.41472138, No.41401220, No.41472026; The CAS Strategic Priority Research Program Grant B, No.XDPB05; The Ministry of Science and Technology of China, No.2016YFA0600503

Author: Lu Huayu, Professor, specialized in long-time climatic change, aeolian and fluvial geomorphology and early human environment reconstruction. E-mail: huayulu@nju.edu.cn 


\section{Introduction}

The physical geography and natural landscape of China is composed of three parts: monsoonal and humid East China, the dry and windy Northwest China and the cold and high Tibetan Plateau in Southwest China. The elevation of the landforms decreases systematically from west to east, in the form of three terraces which decrease in elevation in stepwise fashion. The highest terrain is the Tibetan Plateau, which has an average altitude of $\sim 4000 \mathrm{~m}$. This high elevation region is succeeded by the terrain of the Mongolian-Yungui Plateau, with an altitude of $\sim 2000 \mathrm{~m}$. The lowest terrain is in East China, and is characterized by fluvial-alluvial plains and large deltaic plains, with altitudes of less than $100 \mathrm{~m}$ above sea-level (m a.s.1.) (Figure 1a). The topography of China was formed at least by the early Miocene (Guo et al., 2002; Sun and Wang, 2005), and was controlled by the collision between the Eurasian and Indian Plates in the early Paleocene (Hu et al., 2016), and the growth of the Tibetan Plateau during the late Cenozoic (Molnar et al., 2010). The transformation of tectonic compression stresses resulting from collision and deformation is responsible for creating the landforms of China, as well as the great rivers that flow from the west and north to the east and south (Zheng et al., 2017). At the same time, the high relief probably modulated the balance between thermal sink and source, thereby inducing the Asian monsoonal circulation (Manabe and Broccoli, 1990). In turn, the monsoonal circulation came to dominate major aspects of the physical environment in East Asia. The earth surface processes in most of China are associated with the collision of the Indian-Eurasian Plates and the subsequent carving of the landscape by fluvial erosion resulting from the monsoonal climate. The initiation of the Great Northern Hemisphere Glaciations (GHGs) in the earliest Pleistocene, and the glacial-interglacial alternations in the Pleistocene, have dominated the variability of the Asian monsoon climate; in turn the fluctuations in the monsoon climate have dominated the formation and evolution of landforms and earth surface process (Lu et al., 2010; Lu and Guo, 2014).

The unique landforms and monsoon climate of East Asia, especially in East China, provided a highly suitable habitat for early humans. Moreover, the discoveries of the remains of Peking Man (Homo erectus) at Zhoukoudian and of Nihewan Paleolithic artifacts in the 1920s in northern China (Black, 1932; Xie et al., 2006), were one of the most important events in the exploration of early human history in the 20th century. The earliest evidence of human presence is probably at Nihewan (Hebei Province), an area of lacustrine and fluvial landforms in northern-central China, and is dated to 1.7-1.6 Ma BP (Zhu et al., 2004, 2008). This robustly-dated evidence indicates that these earliest hominins were probably hunter-gatherers, who used simple Oldowan stone tools such as cores, flakes and other lithic artifacts (Xie et al., 2006). After the discovery of Nihewan early man, several excavated sites with human remains and lithic artifacts were found. This well-dated evidence includes Lantian Man ( 1.2 Ma BP), Yunxian Man ( $\sim 0.8 \mathrm{Ma} B P)$, the Chenjiawo mandible $(\sim 0.65$ Ma BP), as well as Dingcun Man, Dali Man and Lushi Man (0.3-0.15 Ma BP). These sites are all in and around the Qinling Mountains (Figure 1). Recently, several late Pleistocene human fossils have been found (Liu et al., 2015; Li et al., 2017), although the dating results are debated. Moreover, the controversial finds of Wushan Man (Huang et al., 1995), Yuanmu Man (Gao, 2015) and the Bose Handaxe assemblage (Wang et al., 2014), are not discussed in this paper. 
(1a)

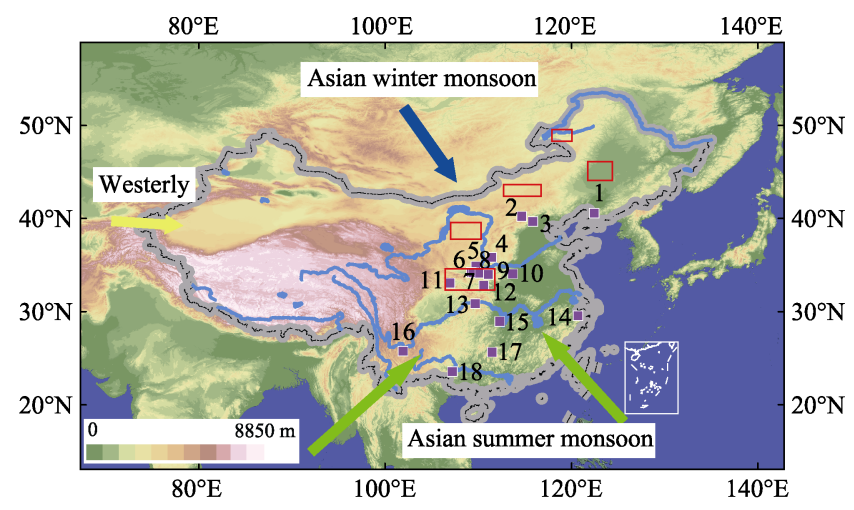

(1b)
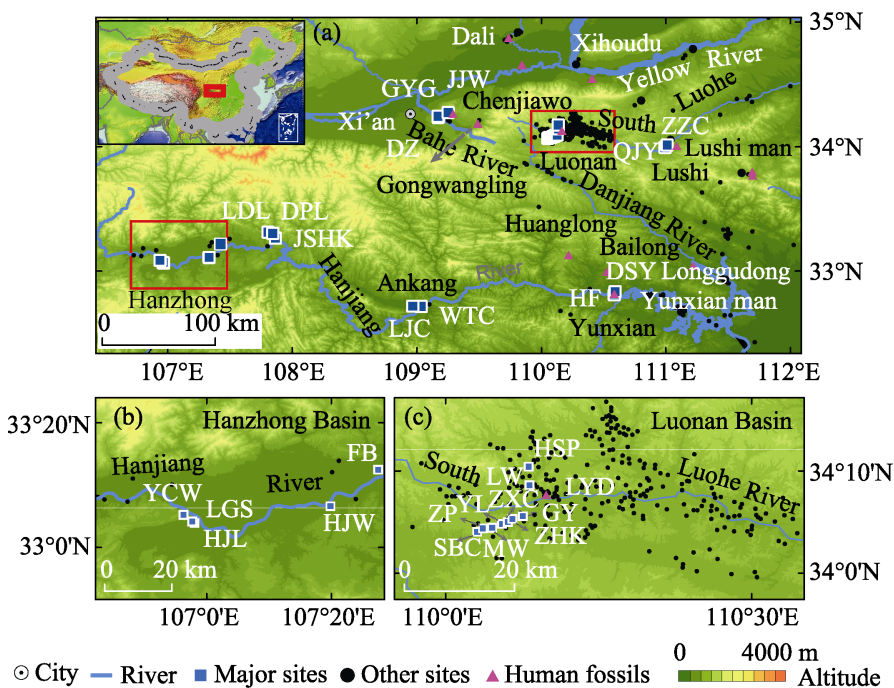

(1c)

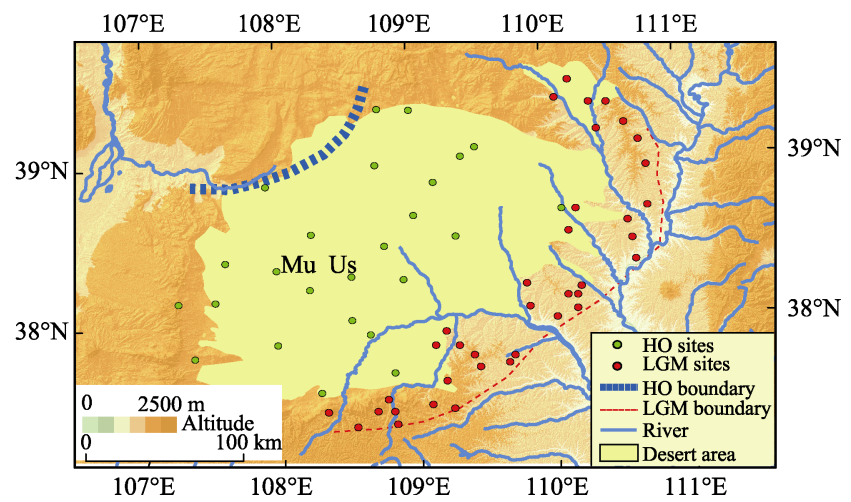

Figure 1 1a. Relief and major atmospheric circulation systems of China. Paleolithic and Neolithic archaeological sites are indicated by solid squares and the study regions mentioned in the text are indicated by hollow rectangles. Sites: 1. Jinniushan; 2. Nihewan; 3. Zhoukoudian; 4. Dingcun; 5. Dali; 6. Chenjiawo; 7. Gongwangling; 8. Luonan; 9. Lushi; 10. Lingjing; 11. Longgangsi; 12. Yunxian man; 13. Wushan; 14. Anjiang; 15. Chishandao; 16. Yuanmou; 17. Daoxian; 18. Bose.

1b. (a) Major basins, drainage patterns and Paleolithic sites in the Eastern and Central Qinling Mountains Region (QMR). (b) and (c) are enlargements of the Hanzhong and Luonan Basins.

1c. Location of Neolithic archaeological sites in the transitional zone between sand dune fields and loess deposits. Solid green circles are Holocene Optimum (HO) sites and solid red circles are Last Glacial Maximum (LGM) sites. 
In addition to these findings, hundreds of thousands Paleolithic artifacts have been collected in monsoonal China (Wang S, 2005; Gao et al., 2016; Wang and Lu, 2016). Over the past 30 years, our research group has collected more than 200,000 lithic artifacts in the Eastern and Central Qinling Mountains Region (QMR) (Wang S, 2005; Wang et al., 2008, 2014; 2015, 2016; Lu et al., 2007, 2011a, 2012; Sun et al., 2012, 2017; Zhuo et al., 2016; Zhuo, 2017, unpublished PhD thesis), and several phases of human occupation were documented (Lu et al., 2007, 2011b, 2012; Sun et al., 2017). The lithic artifacts are densely distributed in the watersheds of the South Luohe River, Hanjiang River and Bahe River (Figure 1c).

In addition, there are a large number of Neolithic excavation sites in the monsoon-dominated region, revealing that human behavior was closely associated with earth surface process and environmental change, particularly in ecologically- sensitive areas such as the transitional zone between desert and loess in North China. We have systematically investigated this area to explore the relationship between human behavior and landform processes and environmental change in the recent geological past (Zhuo et al., 2013; Lu et al., 2013) (Figure 1).

The dense distribution of Paleolithic and Neolithic sites in monsoonal China, which yield important information about human behavior in the Pleistocene and Holocene, are associated with changes in fluvial and aeolian landforms on multiple timescales. Therefore, the region provides an excellent testing ground for examining the relationship between geomorphological processes and human behavior, which hitherto has been largely undocumented in East Asia.

\section{Landform evolution and changes in monsoon climate}

There are major river catchments, mountain-basin systems, the Loess Plateau, dune fields and large alluvial basins and river deltas in eastern and central China, where vegetation growth is sustained by monsoonal precipitation and the fertile soils. The landforms developed much earlier than the timing of early human arrivals. For example, the Qinling Mountains, which are one of the most important biogeographic barriers between South and North China, were formed prior to the early Paleocene (Meng, 2017). However, the topography of the Qinling Mountains was still changing during the late early Pleistocene to Holocene, coinciding with the arrival and occupation of early humans in the area.

The global cooling of the early Pleistocene was accompanied by the growth of ice sheets in the high-latitude Northern Hemisphere, the lowering of sea level and strengthening continentality. At the same time, East Asia became drier because the lower temperatures weakened atmospheric circulation and moisture exchange (Lu et al., 2010). Against this background, the Asian summer and winter monsoon systems were established, and the intensified East Asian winter monsoon transported increased quantities of dust that was deposited in central and northern China, on various landform surfaces, especially on the Chinese Loess Plateau. Aeolian loess deposition resulted in the formation of a major landscape type which was traversed and occupied by Pleistocene hominins. In addition, the loess sediments mantled the fluvial terraces and mountain tops, with thicknesses of several tens to more than three hundred meters. Continuous loess-paleosol sequences are associated with these loess tableland landforms, and they provide excellent archives for reconstructing past climatic and environmental changes (Lu et al., 1999, 2004), as well as enabling the dating of the early 
human relics (Lu et al., 2007, 2011a, 2012). Since loess sediments are fragile and susceptible to erosion, the development of the numerous gullies and cliffs associated with the loess landforms may have impacted early human migration patterns and behavior.

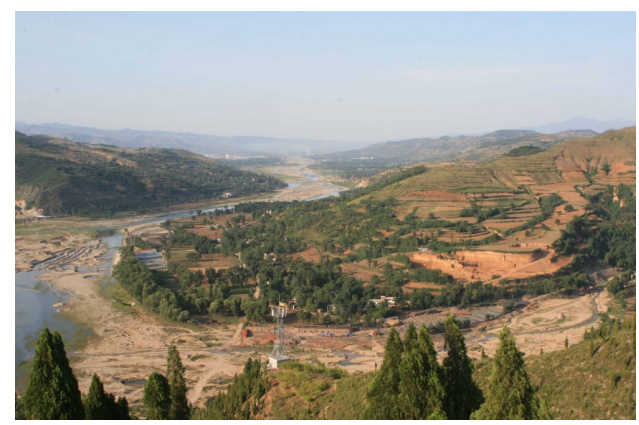

(a) Qiaojiayao loess deposits and fluvial landforms

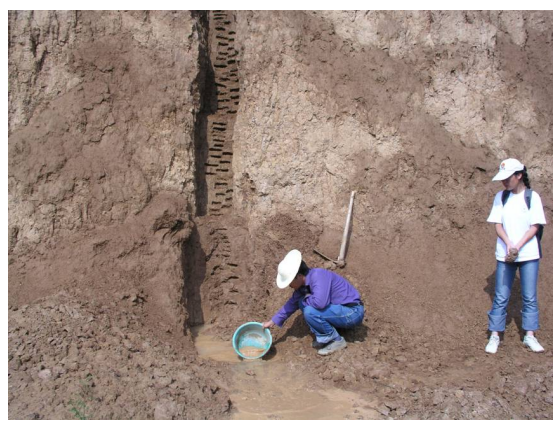

(b) Liuwan loess stratigraphy

Figure 2 Examples of loess landforms and stratigraphy in the Luoshi and Luonan Basins, QMR, central China

The monsoon rainfall water is transported to the sea via a hierarchical network of channels in which gullies, tributaries and rivers are composed of the major fluvial systems. Tectonic uplift in East China during the Pleistocene was less than several tens of meters over most of the region, and therefore the formation of the river terraces was driven mainly by surface erosion and channel migration. The oldest investigated river terraces are $\sim 2.0 \mathrm{Ma} \mathrm{BP}$, but the hominin occupation is dated to as early as $\sim 1.2 \mathrm{Ma}$ BP (An and Ho, 1989; Sun et al., 2017) (Figure 3). Over the past 1.2 Ma BP, more than five river terraces were formed with diverse ages, ranging from early Pleistocene to Holocene. Most of the terraces are in fluvial basins, but some are in broad river channels. Formation of the fluvial terrace sequences was mainly driven by erosion and minor local surface uplift, indicating that local tectonic activity and bedrock erosion may have controlled terrace formation, modulated by climate change.

Long-term fluvial erosion was controlled by alternations in monsoon strength, and channel migration. The Hanjiang River flows through basins and gorges, same as the South Luohe River; however, the Bahe River originates from mountains and flows out into the Guanzhong Basin, and landforms resembling those of the two river systems to the south and southeast are absent due to its much shorter length (Figure 1). River terrace sequences are mainly developed in basins, such as the Hanzhong, Ankang, Yunxian and Shiyan Basins along the Hanjiang River; and the Luonan, Lushi, Luoning and Yiyang Basins along the South Luohe River (Figures 1 and 2). The structure of the fluvial terraces comprises bedrock at the base, followed sequentially upwards by fluvial pebbles and loess-paleosol deposits (Figure 3). Due to its ability to yield precise ages, the loess deposits can provide reliable constraints on the timing of the formation of the river terraces, as well as the ages of the Paleolithic artifact assemblages, which are scattered on the fluvial terrace surfaces and buried in the loess deposits. There are height differences of more than $400 \mathrm{~m}$ between the investigated terraces, and the artifacts buried therein reveal that the patterns of early human migration followed the patterns of terrace evolution.

Landform evolution also occurred on a shorter time scale. In the transitional zone between sand dune fields and loess deposits, within which the climate varies from arid to semiarid, 

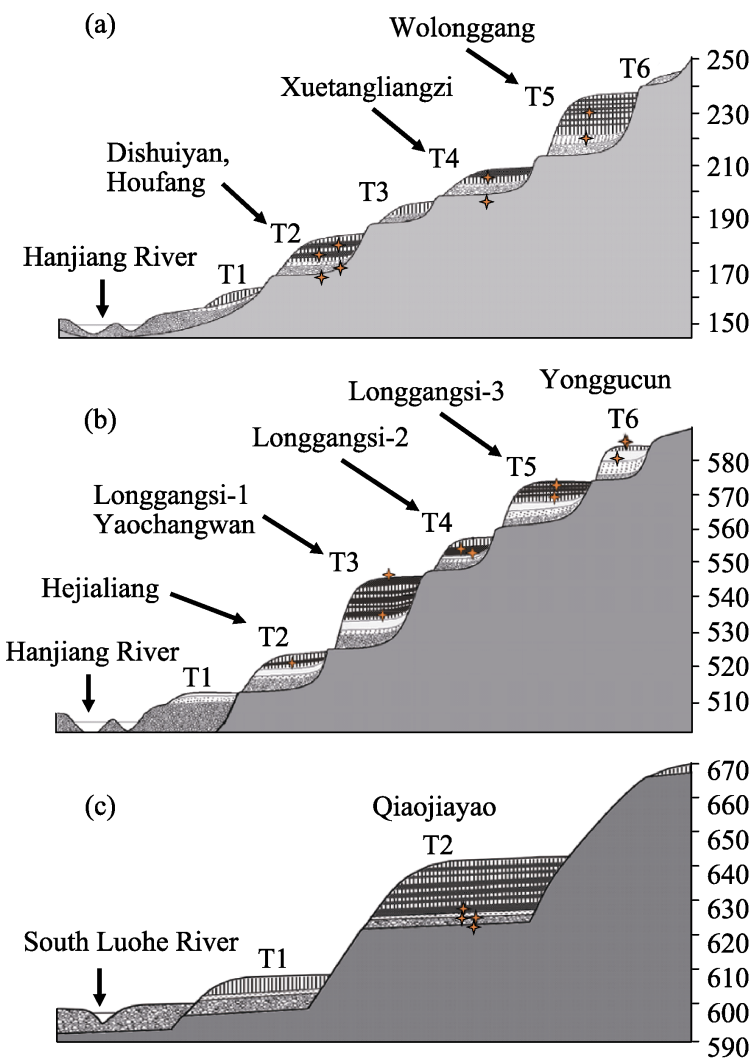

(d)

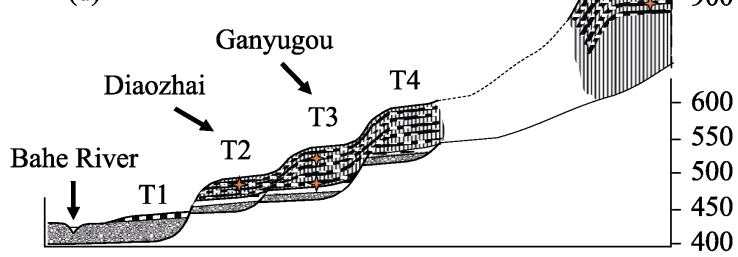

血向 Loess $\quad \square$ Paleosol $\quad \square$ Eolian deposit

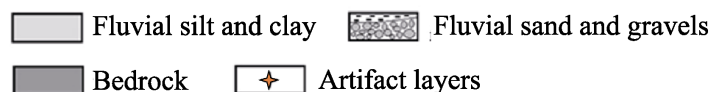

Figure 3 Landforms and fluvial terraces of the Hanjiang River, South Luohe River, and Bahe River, QMR, central China (a. Yunxian site; b. Longgangsi site; c. Qiaojiayao site; d. Diaozai site) the waxing and waning of the monsoon during the past $\sim 20 \mathrm{ka}$ has resulted in significant migration of the boundary. Essentially, a strengthened summer monsoon delivered more rainfall to the dune fields, where water was the critical limiting factor for plant growth. The increased rainfall in turn resulted in a denser vegetation coverage, the sand dunes were stabilized, and fertile soils developed. At the same time, the rivers, lakes and swamps expanded, providing a favorable environment for early humans. On the other hand, a weakened summer monsoon circulation provided insufficient water to maintain the vegetation coverage, resulting in dune mobility and a dusty environment. Under this scenario, alternations in monsoon circulation clearly controlled earth surface processes and modulated the environment of early humans. As the climate became more arid, dune fields such as the Mus Us underwent large-scale expansion and contraction (Figure 4; Lu et al., 2013; Xu et al., 2013), resulting in shifts of biogeographic boundaries of 200-300 km. Similar changes occurred in the sand dune fields of the Otindag (Zhou et al., 2013), Horqin (Yi et al., 2013) and Hulun Bier (Zeng et al., 2013). The shorelines of paleolakes would have shifted along with the changes in monsoon precipitation and lake levels (Jiang Mengyao, 2017. Personal communication). This was significant for early humans since they probably migrated in response to the lake shoreline changes. In the Nihewan Basin, the region with the earliest evidence of human occupation in East Asia, excavations have discovered lithic tools buried in lake sediments. This can be interpreted as evidence of lake transgression under increased summer monsoon precipitation. Therefore, lake expansion and contraction, resulting from changes in summer monsoon intensity, and the accompanying changes in lake shorelines, may have significantly impacted the environment of early humans. Since $\sim 1.7 \mathrm{Ma}$ BP, more than 


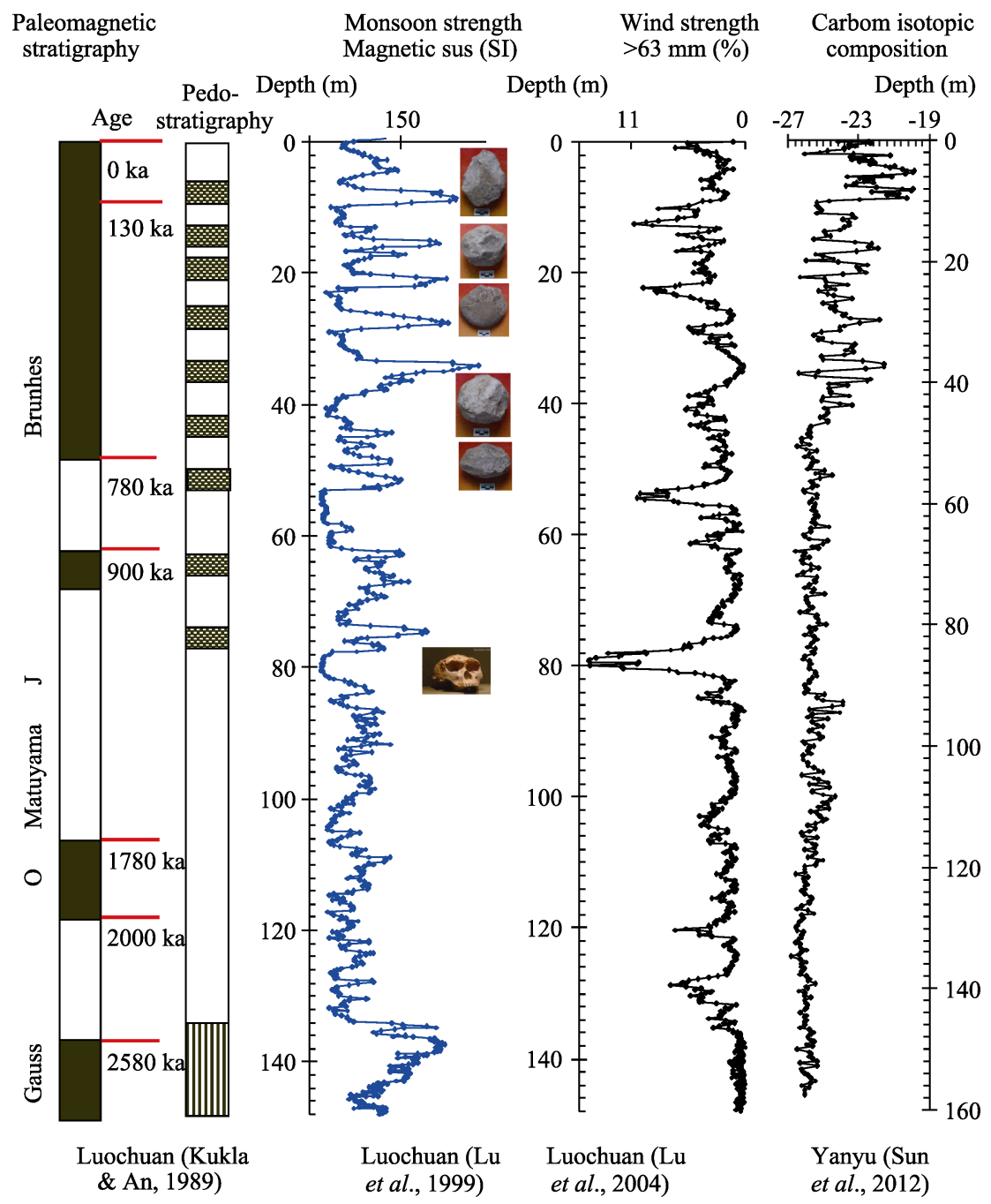

Figure 4 Stratigraphy and paleoenvironmental records from the Chinese Loess Plateau spanning the last 2 Ma. From left to right: geomagnetic polarity time scale; pedostratigraphy of the loess-paleosol sequence; magnetic susceptibility record of the Luochuan site, reflecting variations in summer monsoon strength; grain-size record from Luochuan, reflecting winter monsoon strength; stable carbon isotopic composition from the Yanyu site, reflecting vegetation patterns. The major climatic trends and cyclicity are linked with the evolution of the behavior of early humans.

130-m lake sediments have accumulated, with an area of $\sim 1800 \mathrm{~km}^{2}$ (Zhu et al., 2004; Xie et al., 2006). This clearly demonstrates the occurrence of significant changes in lacustrine landforms in the Pleistocene.

Thus, variations in the monsoonal climate have significantly shaped the landforms occupied by early humans in central and northern China since the early Pleistocene, including fluvial incision, modulation of the area of dune fields, and changing the position of lake shorelines. The driving force behind these changes in earth surface processes and the resulting landforms was the fluctuating monsoonal climate. Fortunately, the Chinese loess-paleosol sequences, which provide a unique record of changes in the monsoon climate and the associated vegetation, also yield direct evidence of early human occupation and behavior. Nota- 
ble among the proxy climatic indicators applied to loess deposits are the magnetic susceptibility which reflects summer monsoon precipitation; the stable carbon isotopic composition which reflects vegetation composition, specifically changes in the relative coverage of woodland and grassland; and the sediment grain-size distribution which reflects the winter monsoon strength and the area of mobile dune fields (Lu et al., 2004; Sun Jimin et al., 2012). Fluctuations in precipitation, temperature, wind strength and vegetation since the early Pleistocene are illustrated in Figure 4.

\section{Human behavior during the Pleistocene and Holocene: evidence from the QMR region and dune fields}

To date, we have collected more than 200,000 lithic artifacts from the QMR region. These findings indicate that early humans occupied the river terraces of the South Luohe River, Hanjiang River and Bahe River for a very long interval of time (Figure 4). They arrived in the QMR region, in both the north and south, and may have occupied the area semi-continuously until the last few tens of ka, probably with several phases of intensive activity (An and Ho, 1989; Lu et al., 2007, 2011a, b; 2012; Wang S J et al., 2005, 2008, 2014, 2016; Zhuo et al., 2016; Sun et al., 2012, 2013, 2017). The sites of early human settlement are located on river terraces within the range of several meters to hundred meters above the river water level, revealing that the humans moved across a large area. During several phases of occupation there are linkages between the southern and northern QMR; for example, at 1.2 Ma hominins occupied both Longgansi site in the south and Gongwangling site in the north QMR (An and Ho, 1989; Sun et al., 2017). This demonstrates that the early humans may have moved across the Qinling Mountains; this is also supported by the close similarity of the lithic tool technology at the two sites, which indicates a direct linkage. After the earliest arrival in the QMR, the early humans dispersed over a large area, with a diameter of more than $200 \mathrm{~km}$. The ages of the sites are clustered within specific ranges: 800-600 ka BP, 500-400 ka BP, 400-200 ka BP, 200-100 ka BP, and the last $50 \mathrm{ka}$ (Lu et al., 2007, 2011a, b, 2012; Wang et al., 2005, 2008, 2014, Sun et al., 2012, 2017; Zhuo et al., 2016; Wang and $\mathrm{Lu}, 2016)$. These results clearly indicate that the Qinling Mountains, with an average altitude of $\sim 2000 \mathrm{~m}$, did not act as a barrier to the migration of humans during the early to middle Pleistocene. It appears that in the QMR the early humans moved along rivers and channels to a greater extent than was previously realized. Our observations do not support the idea that the elevation of the Qinling Mountains was lower during the early Pleistocene than it is today (Xue et al., 2004), and that populations of hominins were eventually communicated between the south and north QMR. The fluvial landforms and basins in the QMR were mainly modified by climate change during the Pleistocene, and the stepped sequence of river terraces, dated from $\sim 2.0 \mathrm{Ma} B P$ to $\sim 0.01 \mathrm{Ma} \mathrm{BP}$, may have provided easy access of early humans to water bodies. It suggests that as the river terraces were formed the early humans may have shifted their gathering and occupation areas to the lower terraces. This hypothesis is supported by the early human occupation sites at Longyadong Cave (Wang, 2005), Liuwan (Lu et al., 2007; Zhang et al., 2012), Qiaojiayao (Lu et al., 2011a), Hejialiang (Sun et al., 2012; Wang et al., 2014) and Longgangsi (Sun et al., 2017; Wang and Lu, 2016). Our recently excavated sites, such as Fanba (Figure 5a), Duanping (Figure 5b), 


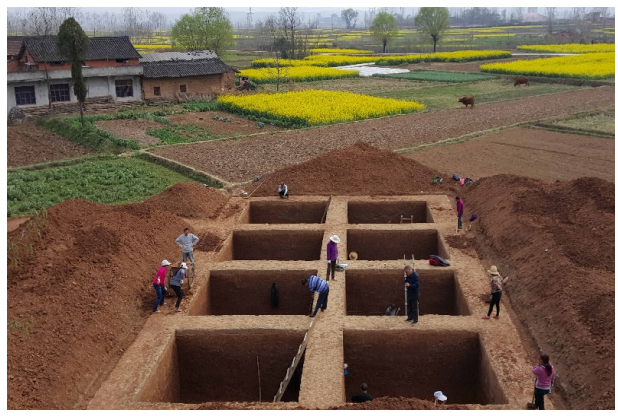

(a) Field excavation at Fanba (2016)

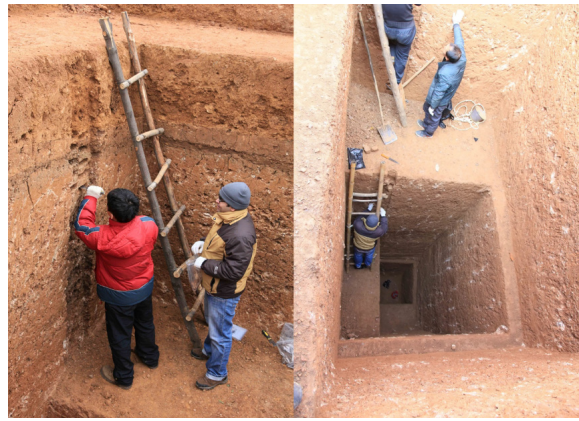

(c) Field excavation at Jinshui (2016)

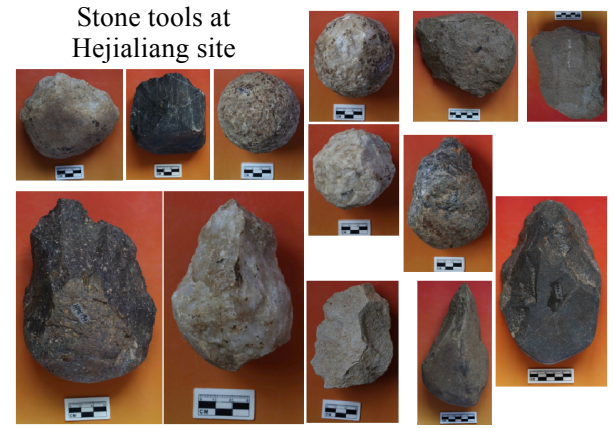

(e) Paleolithic tool assemblage from the Hanzhong Basin (2016)

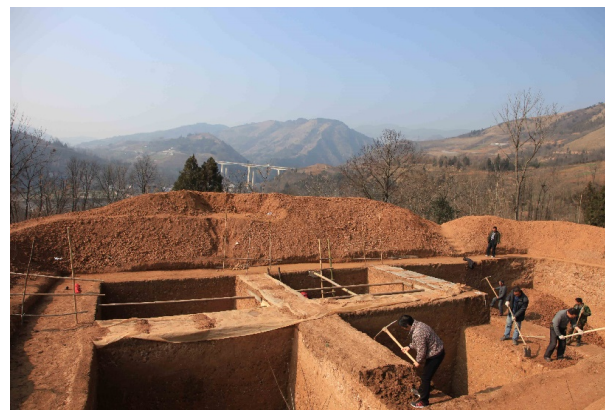

(b) Field excavation at Duanping (2016)

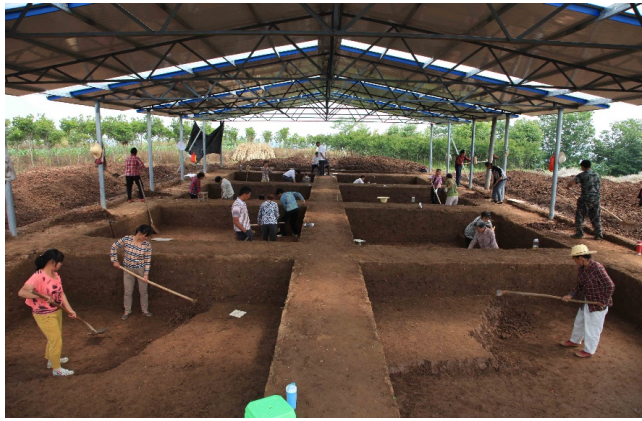

(d) Field excavation at Longgangsi (2016)

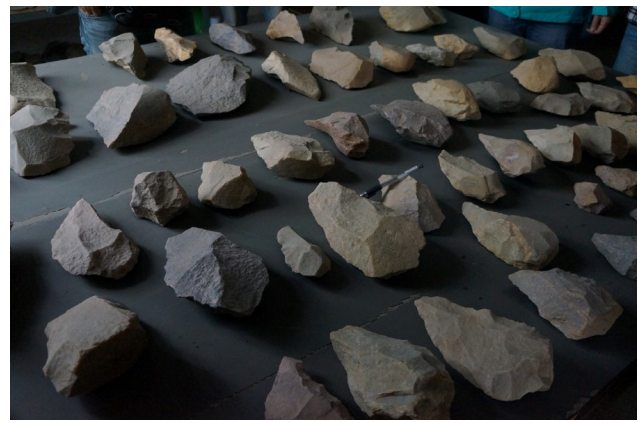

(f) Typical stone tools from the Luonan Basin (2013)

Figure 5 Recent archaeological findings in the QMR, central China

Jinshui (Figure 5c) and Longgangsi (Figure 5d), share the same features. We have found numerous lithic artifact assemblages at these sites (Figure 5e, 5f), indicating that the early humans moved in response to changes in the location of water bodies under specific landform constraints.

We have discovered numerous early human occupation sites in various fluvial terraces along the QMR, which are always located in medium-sized intermontane basins and small hills with an approximate diameter of several tens kilometers and elevation of several hundred meters. However, no early human sites have been found in the great plains and alluvial fans; nor have early human remains been found in great loess tableland, such as in the 
Guanzhong Basin and the Bailuyuan and Luochuan loess tablelands. These observations shed light on the attraction of fluvial landforms for the early humans; in addition, the discoveries indicate that they could move from the upper to the lower branches along a river, over distances of 100-300 km.

Other important Paleolithic sites are distributed along river terraces, such as those that yielded remains of Peking Man, Yunxian Man, Dali Man, and Dingcun Man; sites such as in Bose Basin; the recently discovered site of Chishandao, near Yuanjiang city, Hunan Province in South China; and the site at Anjiang, Shengzhou city, Zhejiang Province, in Southeast China. In addition, the famous Nihewan sites such as Dongutuo and Xiaochangliang are located close to lakes, indicating that landforms close to water bodies were the favored locations of early human occupations. Ease of access to water resources was probably the most important factor determining the location of the occupations sites, despite the ability of the early humans to move across a large area.

Even in the very recent geological past, the archaeological sites indicate that the location of occupation sites was closely associated with landform evolution (Zhuo et al., 2013; Lu et al., 2013; Jia et al., 2016, 2017), we therefore speculate that changes in earth surface processes, which influenced vegetation patterns and soil formation, must have impacted human behavior. In the sand dune fields, human relics dating to the Last Glacial Maximum (LGM, $\sim 21 \mathrm{ka} \mathrm{BP}$ ) are relatively rare, but those dating to the Holocene Optimum ( $\mathrm{HO}, 8-5 \mathrm{ka} \mathrm{BP})$ are common (Figure 1c). The sparsity of human sites during the LGM reflects the climatic aridity which resulted in the desiccation of rivers and lakes and the consequent reduced availability of water resources. On the other hand, the increased monsoon precipitation during the $\mathrm{HO}$ resulted in plentiful water resources, enabling the growth of larger vegetation cover and denser populations in the dune fields (Lu et al., 2013). Therefore, patterns of human behavior and settlement were directly determined by earth surface processes on orbital to millennial timescales.

\section{Adaptation of the behavior of early humans to landform evolution}

The populations of early humans may have been replaced by, or intermingled with, migrants. Our new observations shed light on specific landforms and patterns of climate change that together impacted human behavior, as reflected in the occupation sites, movement, reproduction, and prosperity of the populations. Three observations can be made. Firstly, it appears that Northwest China was too dry to have been inhabited by early humans and no early human sites have been found so far. It is possible that early human sites may yet be found in Northwest China. In addition, occupation of the Tibetan Plateau would have been a major challenge for the early humans, because of its cold climate. However, recent discoveries indicate that that humans may have perennially occupied in the Tibetan Plateau in the late Holocene against a background of technological innovation (Chen et al., 2015), may arrived in there earlier (Zhang and Li, 2002; Meyer et al., 2017). Since humans could adapt to the harsh environment, it is possible that even older evidence may be found (Zhao et al., 2009). Nevertheless, clearly the timing of the occupation of the region was significantly later than the arrival of early humans in central China. 
Secondly, the great loess tablelands, although densely occupied by modern people, were also an unfavorable environment for early human occupation and no relics have been discovered. The loess sediments have a poor water retention capacity and therefore the Loess Plateau is always dry even when there is moderate precipitation. In addition, we speculate that transit across the loess landforms would have been difficult, especially during intervals of high rainfall.

Thirdly, the great basins and alluvial plains, comprising a large area in the monsoonal region, may also have been unfavorable for occupation by early humans. No fossils or stone tools have been found associated with these landforms, either on

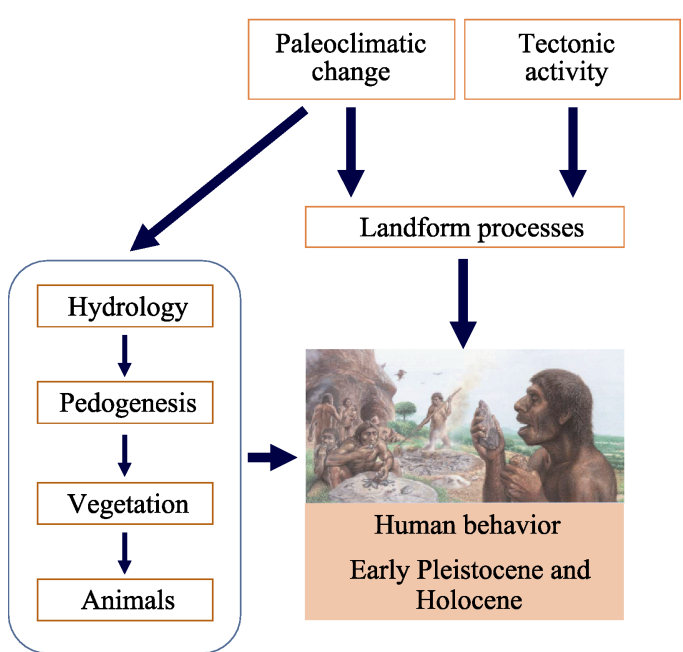

Figure 6 Early human behavior and the major influencing factors in monsoonal China. Surface processes were a major determinant of the behavior of early humans. the surface or buried. The reason may be the occurrence of flooding and predation by carnivores that forced the early humans to occupy the mountains and moderate-sized basins that were more secure.

Despite the great diversity of landforms in monsoonal China, our evidence indicates that in the QMR early humans chose to occupy moderate- and small-sized river valleys, paired mountain-basins and dolomite caves which provided easy access to water resources and abundant plant resources. In summary, first, low hills with moderate-sized basins and rivers were the preferred environment of early humans. Second, it was important to have a reasonable area to move across, that is, to be able to walk or run distances of several to several tens of $\mathrm{km}$. Third, plentiful plant resources close to the occupation sites human settlements were required (Zhang et al., 2017). Landforms determined the local hydrology, climate, and soil development, and thus the vegetation composition, and in turn impacted human behavior (Figure 6). The vegetation and niche environments were also a determinant of early human occupation, but their specific roles need to be further investigated.

From the foregoing analysis, there is no doubt that earth surface processes and landforms were important constraints on the behavior of early humans in monsoonal China; moreover, rapid landform change also clearly impacted human behavior in the very recent geological past. The early humans dispersed along landforms in East Asia, they arrived in middle to small sized hills and basins in Early Pleistocene and early Middle Pleistocene, they occupied the dry areas, highlands such as desert and Tibetan Plateau in Late Pleistocene and Holocene, these evidences may show that the humans have adapted their behaviors to the harsh natural environment with stepwise forward. Overall, our observations demonstrate that landform evolution must have played an important role in modulating human behavior in East Asia during the Pleistocene and Holocene. 


\section{Conclusions}

Our analysis of earth surface processes and the behavior of early humans in China has revealed that specific landforms played an important role in determining patterns of human behavior and the location of occupation sites during the Pleistocene and Holocene. Northwest China and the Tibetan Plateau were too arid and cold for human occupation, until the late Holocene. The oldest early human occupation sites are the Nihewan Basin, in central-northern China, dated to $\sim$.7 Ma BP. The subsequent occupation phases such as in the Qinling Mountains Region during the middle to late Pleistocene provide direct evidence that monsoonal China was a favorable environment for early humans. Moderate-sized rivers and basins and mountains were preferred locations and the vast open plains, basins and loess tablelands were avoided. Easy access to water resources was an important determinant of the occupation sites. Rapid landform change had the effect of driving the human migration, suggesting that earth surface processes had an important impact on early human behavior.

\section{Acknowledgements}

We are grateful to Prof. Sun Jimin for providing stable carbon isotope data of Yanyu loess-paleosol sequence of Figure 4. We thank Dr. Jan Bloemendal for improving the English. This is a contribution to the 9th International Conference on Geomorphology (New Delhi, India, 2017).

\section{References}

An Z S, Ho C K, 1989. New magnetostratigraphic dates of Lantian Homo erectus. Quaternary Research, 32 : 213-221.

Black D, 1932. The discovery of Peking Man. Nature, 130(3294): 935.

Chen F H, Dong G H, Zhang D J et al., 2015. Agriculture facilitated permanent human occupation of the Tibetan Plateau after 3600 B.P. Science, 347(6219): 248-250.

Gao X, 2015. On the age of Homo erectus yuanmounensis and related issues. Acta Anthropologica Sinica, 34(4): 442-450. (in Chinese)

Guo Z T, 2017. Loess Plateau attests to the onsets of monsoon and deserts. Scientia Sinica Terrae, 47: $421-437$. (in Chinese)

Guo Z T, Ruddiman W F, Hao Q Z et al., 2002. Onset of Asian desertification by 22 Myr ago inferred from loess deposits in China. Nature, 416(6877): 159-163.

Hu X M, Garzanti E, Wang J G et al., 2016. The timing of India-Asia collision onset: Facts, theories, controversies. Earth-Science Reviews, 160: 264-299.

Huang W P, Ciochon R, Gu Y M et al., 1995. Early Homo and associated artifacts from Asia. Nature, 378(6554): $275-278$.

Jia X, Lee H F, Zhang W C et al., 2016. Human-environment interactions within the West Liao River Basin in northeastern China during the Holocene Optimum. Quaternary International, 428: 10-17.

Jia X, Yi S W, Sun Y G et al., 2017. Spatial and temporal variations in prehistoric human settlement and their influencing factors on the south bank of the Xar Maron River, northeastern China. Frontiers of Earth Science, 11(1): 137-147.

Li Z Y, Wu X J, Zhou L P et al., 2017. Late Pleistocene archaic human crania from Xuchang, China. Science, 
355(6328): 969-972.

Liu W, Martinon-torres M, Cai Y J et al., 2015. The earliest unequivocally modern humans in southern China. Nature, 526: 696-699.

Lu H Y, Guo Z T, 2014. Evolution of the monsoon and dry climate in East Asia during late Cenozoic: A review. Science China: Earth Sciences, 57(1): 70-79.

Lu H Y, Liu X D, Zhang F Q et al., 1999. Astronomical calibration of loess-paleosol deposits at Luochuan, central Chinese Loess Plateau. Palaeogeography, Palaeoclimatolpgy, Palaeoecology, 154: 237-246.

Lu H Y, Sun X F, Wang S J et al., 2011a. Ages for hominid occupation in Lushi Basin, middle of South Luohe River, central China. Journal of Human Evolution, 60: 612-617.

Lu H Y, Wang X Y, Li L P, 2010. Aeolian sediment evidence that global cooling has driven late Cenozoic stepwise aridification in central Asia. Geological Society, London: Special Publications, 342: 29-44.

Lu H Y, Yi S W, Xu Z W et al., 2013. Chinese deserts and sand fields in Last Glacial Maximum and Holocene Optimum. Chinese Science Bulletin, 58(33): 2775-2783.

Lu H Y, Zhang F Q, Liu X D et al., 2004. Periodicities of palaeoclimatic variations recorded by loess-paleosol sequence in China. Quaternary Science Reviews, 23(18/19): 1891-1900.

Lu H Y, Zhang H Y, Sun X F et al., 2012. Landform, loess deposit and palaeoenvironmental changes in the South Luohe River (central China) during the hominin occupations. Quaternary Sciences, 32: 167-177. (in Chinese)

Lu H Y, Zhang H Y, Wang S J et al., 2007. A preliminary survey on loess deposit in eastern Qinling Mountains (central China) and its implication for estimating age of the Pleistocene lithic artifacts. Quaternary Sciences, 27(4): 559-567. (in Chinese)

Lu H Y, Zhang H Y, Wang S J et al., 2011b. Multiphase timing of hominin occupations and the paleoenvironment in Luonan Basin, central China. Quaternary Research, 76: 142-147.

Manabe S, Broccoli A J, 1990. Mountains and arid climates of middle latitudes. Science, 247(4939): $192-195$.

Meng Q R, 2017. Origin of the Qinling Mountains. Scientia Sinica Terrae, 47: 412-420. (in Chinese)

Meyer M C, Aldenderfer M S, Wang Z et al., 2017. Permanent human occupation of the central Tibetan Plateau in the early Holocene. Science, 355(6320): 64-67.

Molnar P, Boos W R, Battisti D S, 2010. Orographic controls on climate and paleoclimate of Asia: Thermal and mechanical roles for the Tibetan Plateau. Annual Review of Earth \& Planetary Sciences, 38(1): 77-102.

Sun J M, Lü T Y, Zhang Z Q et al., 2012. Stepwise expansions of $\mathrm{C}_{4}$ biomass and enhanced seasonal precipitation and regional aridity during the Quaternary on the southern Chinese Loess Plateau. Quaternary Science Reviews, 34: 57-65.

Sun X F, Lu H Y, Wang S J et al., 2012. Ages of Liangshan Paleolithic sections in Hanzhong Basin, central China. Quaternary Geochronology, 10: 380-386.

Sun X F, Lu H Y, Wang S J et al., 2013. TT-OSL dating of Longyadong Middle Paleolithic site and paleoenvironmental implications for hominin occupation in Luonan Basin (central China). Quaternary Research, 79: $168-174$.

Sun X F, Lu H Y, Wang S J et al., 2017. Early human settlements in the southern Qinling Mountains, central China. Quaternary Science Reviews, 164: 168-186.

Sun X J, Wang P X, 2005. How old is the Asian monsoon system? Palaeobotanical records from China. Palaeogeography, Palaeoclimatology, Palaeoecology, 222(3/4): 181-222.

Wang S J, 2005. Perspectives on hominin behavior and settlement patterns: A study of the lower Paleolithic sections in the Luonan Basin, China. In: British Archaeological Reports International Series 1406. Oxford: Archaeopress.

Wang S J, Lu H Y, 2016. Taphonomic and paleoenvironmental issues of the Pleistocene loessic Paleolithic sites in the Qinling Mountains, central China. Science China Earth Sciences, 59: 1519-1528.

Wang S J, Lu H Y, Zhang H Y et al., 2008. A preliminary survey of palaeolithic artifacts and loess deposition in 
the middle South Luohe River, eastern Qinling Mountains, central China. Quaternary Sciences, 28: 988-999. (in Chinese)

Wang S J, Lu H Y, Zhang H Y et al., 2014a. Newly discovered palaeolithic artifacts from loess deposits and their ages in Lantian, central China. Chinese Science Bulletin, 59(7): 651-661.

Wang S J, Sun X F, Lu H Y et al., 2014b. Newly discovered Paleolithic open-air sites in Hanzhong Basin in upper valley of Hanjiang River and their ages. Acta Anthropologica Sinica, 22(2): 125-136. (in Chinese)

Wang W J, Bae C, Huang S M et al., 2014. Middle Pleistocene bifaces from Fengshudao (Bose Basin, Guangxi, China). Journal of Human Evolution, 69: 110-122.

Xie F, Li J, Liu L Q, 2006. Paleolithic Archeology in the Nihewan Basin. Shijiazhuang: Huashan Literature and Arts Press. (in Chinese)

Xu Z W, Lu H Y, Yi S W et al., 2013. Spatial variations of the Mu Us dune field (north central China) during the Last Glacial Maximum and Holocene Optimum. Quaternary Sciences, 33(2): 218-227. (in Chinese)

Xue X X, Li H H, Li Y X, 2004. The new data of the uplifting of Qinling Mountains since the Middle Pleistocene. Quaternary Sciences, 24(1): 82-87. (in Chinese)

Yi S W, Lu H Y, Zeng L et al., 2013. Paleoclimate changes and reconstruction of the border of Horqin dunefield (northeastern China) since the Last Glacial Maximum. Quaternary Sciences, 33(2): 207-217. (in Chinese)

Zeng L, Lu H Y, Yi S W et al., 2013. Environmental changes of Hulun Buir Dunefield in northeastern China during the Last Glacial Maximum and Holocene Optimum. Quaternary Sciences, 33(2): 243-251. (in Chinese)

Zhang D D, Li S H, 2002. Optical dating of Tibetan human hand- and footprints: An implication for the palaeoenvironment of the last glaciation of the Tibetan Plateau. Geophysical Research Letters, 29: 1-3.

Zhang H Y, Lu H Y, Jiang S Y et al., 2012. Provenance of loess deposits in the eastern Qinling Mountains (central China) and their implications for the paleoenvironment. Quaternary Science Review, 43: 94-102.

Zhang H Y, Lu H Y, Wang S J et al., 2017. Consistent C3 plant habitat of hominins during 400-300 ka at the Longyadong Cave site (Luonan Basin, central China) revealed by stable carbon isotope analyses of loess deposits. Journal of Human Evolution, 108: 1-10.

Zhao M, Kong Q P, Wang H W et al., 2009. Mitochondrial genome evidence reveals successful Late Paleolithic settlement on the Tibetan Plateau. PNAS, 106(50): 21230-21235.

Zhou Y L, Lu H Y, Zhang H Y et al., 2013. Changes of the border of Otindag Sand Field (Northern China) during the Last Glacial Maximum and Holocene Optimum. Quaternary Sciences, 33(2): 228-242. (in Chinese)

Zhu R X, Potts R, Pan Y X et al., 2008. Early evidence of the genus Homo in East Asia. Journal of Human Evolution, 55: 1075-1085.

Zhu R X, Potts R, Xie F et al., 2004. New evidence on the earliest human presence at high northern latitudes in northeast Asia. Nature, 431: 559-562.

Zhuo H X, 2017. Hominid ages and paleoenvironment based on the analyses of Pleistocene loess deposits in Lantian, central China [D]. Nanjing: Nanjing University.

Zhuo H X, Lu H Y, Jia X et al., 2013. A preliminary study on human activities in sand fields of northern China and its relationship with the climatic variations in Holocene. Quaternary Sciences, 33(2): 303-313. (in Chinese)

Zhuo H X, Lu H Y, Wang S J et al., 2016. Chronology of newly-discovered Paleolithic artifact assemblages in Lantian (Shaanxi province), central China. Quaternary Research, 86: 316-325. 